\title{
BRIEF
}

\section{Implementation and Assessment of a Heart Failure Virtual Patient Simulation in a Required Pharmacotherapy Course}

\author{
Ashley E. Woodruff, PharmD, ${ }^{\text {a }}$ Maya R. Chilbert, PharmD, ${ }^{\text {a }}$ William A. Prescott, Jr., PharmD, ${ }^{a, b}$ Nicole \\ Wilcox, PharmD, ${ }^{\mathrm{c}}$ Omar Marzouk, PharmD, ${ }^{\mathrm{d}}$ Gina M. Prescott, PharmD, ${ }^{\mathrm{a}}$ Erin M. Slazak, PharmD ${ }^{\mathrm{a}}$ \\ ${ }^{a}$ University at Buffalo, School of Pharmacy and Pharmaceutical Sciences, Buffalo, New York \\ ${ }^{\mathrm{b}}$ Editorial Board Member, American Journal of Pharmaceutical Education, Arlington, Virginia

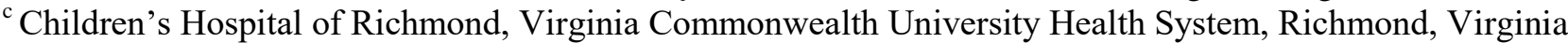 \\ ${ }^{\mathrm{d}}$ Dana-Farber Cancer Institute, Boston, Massachusetts
}

Corresponding Author: Ashley E. Woodruff, University at Buffalo, School of Pharmacy and Pharmaceutical Sciences, 205 Pharmacy Bldg., Buffalo, NY 14214. Tel: 716-645-1734. Email: aew7@buffalo.edu

Submitted March 22, 2021; accepted September 8, 2021; ePublished September 2021

Objective. To assess academic performance and student perception of a heart failure (HF) virtual patient simulation used in a required pharmacotherapy course in the fall of the second professional year.

Methods. A HF virtual patient simulation was created to augment HF pharmacotherapy course material at the University at Buffalo School of Pharmacy and Pharmaceutical Sciences in the fall of 2019. This was a retrospective, pre-post, observational cohort study. The primary objective was to compare performance on HF pharmacotherapy examination questions in a cohort of students who completed a virtual patient simulation in 2019 compared to a control cohort who completed a paper-based case activity in 2018. Student perceptions of the simulation experience were assessed via electronic survey.

Results. All students completed either the virtual patient simulation $(\mathrm{n}=122)$ or paper-based case activity $(\mathrm{n}=123)$. Overall, the proportion of correctly answered HF pharmacotherapy examination questions was $83.3 \%$ in 2019 compared to $79.2 \%$ in 2018 . Student survey results indicated a preference for incorporation of virtual patient simulation in the pharmacotherapy curriculum.

Conclusion. The use of a HF virtual patient simulation was associated with improved examination performance and was well received by student users.

Keywords: pharmacy education, simulation, virtual patient, heart failure, pharmacotherapy

\section{INTRODUCTION}

In health care, a simulated-based learning experience is defined as, "an array of structured activities that represent actual or potential situations in education and practice. These activities allow participants to develop or enhance their knowledge, skills, and attitudes, or to analyze and respond to realistic situations in a simulated environment". Simulation has been used in pharmacy education and across the health care disciplines using various modalities including live human simulations, human patient simulators that have realistic human physiologic responses, game-based simulations, and computer-based simulations including virtual patients. ${ }^{2-5}$ Virtual patients are computer programs that simulate clinical scenarios in an authentic manner allowing the learner to serve as the health care professional making clinical decisions in a realistic, yet, innocuous environment. ${ }^{6}$ These simulations can promote problem solving, self-directed learning, and enhance clinical skills., ${ }^{3,-8}$

Heart failure (HF) is a commonly encountered disease state projected to affect nearly eight million people in the US by 2030. ${ }^{9}$ Pharmacists have been shown to increase medication adherence, decrease readmission rates, prevent adverse drug events, and decrease costs of care by optimizing HF treatment, making this an ideal disease state for utilization of virtual patient simulations. ${ }^{10}$ At the University at Buffalo School of Pharmacy and Pharmaceutical Sciences (UB SPPS), pharmacotherapeutic HF content is taught in the fall of professional year (PY) two. Since this content is covered fairly early in the curriculum, a virtual patient simulation was created to provide immediate and individualized feedback to better facilitate learning. The purpose of this study was to evaluate the utility and perceptions of this technology. 


\section{METHODS}

This was a retrospective study that evaluated HF examination question performance after use of a HF virtual patient simulation in a three-credit hour, required pharmacotherapy course. Four didactic lectures were devoted to HF content delivered by the same instructor in 2018 (control cohort) and 2019 (intervention cohort) using the same content and learning objectives. Learning objectives were: (1) Define heart failure with reduced ejection fraction (HFrEF) and preserved ejection fraction (HFpEF); (2) Explain the pathophysiology of HF and how it relates to drug therapy targets; (3) Recommend an optimal treatment regimen for a patient with HFrEF to decrease morbidity and mortality, including discontinuation and titration of therapies; (4) Recommend optimal treatment across the continuum of heart failure care (ie, a patient at risk of developing HF, a patient with chronic HF and a patient with acutely decompensated HF; and (5) Monitor the safety and efficacy of recommended HF therapies. Lectures were delivered in a live, lecture hall setting but were recorded and posted on the course site for students wishing to review the lecture material again. Table 1 compares the relevant classroom information between years. The simulation addressed all HF learning objectives but was specifically designed to enhance learning objective 4 above.

Clinical casework was assigned as a supplement to lecture material. This was comprised of "static" paper-based cases (one day of patient subjective/objective information from hospital admission) with short answer questions and an optional case debrief recitation in 2018. This was replaced with an evolving, branched-linear, virtual patient simulation in 2019. The simulation followed the clinical time course of a single HF patient through the continuum of HF care (initial myocardial infarction, ADHF emergency department presentation, and advanced HF hospital admission) with associated clinical questions. The simulation contained 13 multiple choice, clinical questions with specific feedback provided to the student based on their response. If answered incorrectly, students were routed back to the question again for re-attempt and only allowed to progress in the simulation once each question was answered correctly. Students were allowed to go through the simulation as many times as desired. The simulation was created using Adobe Captivate 2019 release (Adobe Systems Incorporated, San Jose, California) with a one-time cost of \$399 (individual educator license) and was uploaded as a Sharable Content Object Reference Model (SCORM) package in the course learning management system (LMS), Blackboard (Blackboard, Inc., Washington DC). Two elective Advanced Pharmacy Practice Experience (APPE) students created the simulation over two weeks with a faculty mentor who spent about 20 hours reviewing and editing their work.

The primary objective was HF question performance on course examinations [an individual examination within the course assessing HF (section examination) and the cumulative final examination (final examination)]. The proportion of HF questions answered correctly were compared pre-simulation in 2018 (control) to post-simulation in 2019. Question performance was also assessed across Bloom's taxonomy levels to evaluate differences in lower (knowledge/comprehension) vs. higher (application/synthesis) order questions as assigned a priori by the primary investigator (HF instructor) and confirmed by a second instructor in the course. ${ }^{11}$ Examination questions were kept the same each year; however, schedule differences resulted in four additional HF questions in 2019. See table 1 for question breakdown between years.

The secondary objective was to assess student perceptions of the simulation from a survey administered after the HF section examination created in SurveyMonkey (SurveyMonkey Inc., San Mateo, California). The survey contained questions pertaining to student perception of the simulation experience using a Likert scale (1-5) and an open-ended free text question asking for any additional comments, particularly strengths and weaknesses of the simulation experience. Survey completion was voluntary and anonymous and did not impact student examination or final course grades.

Differences in the proportion of HF examination questions answered correctly between years were compared using chi-square test, including comparisons across Bloom's taxonomy levels. Descriptive statistics were used to summarize the student perception survey data and qualitative content analysis was performed by the primary investigator to assess themes in the comments section of the survey. A $p$-value $<0.05$ was set as significant. All statistical analyses were completed using Prism version 8.0 (GraphPad Software, San Diego, California). The Institutional review board (IRB) granted this project an exemption from review.

\section{RESULTS}

There were 123 students enrolled in the course in 2018 and 122 in 2019. All students completed either the paperbased HF case or the virtual patient simulation. Examination performance is detailed in table 2. The proportion of correctly answered HF pharmacotherapy (section examination and final examination) questions was $79.2 \%$ in 2018 compared to $83.3 \%$ in $2019, p=.001$.

Eighty-five students completed the simulation perception survey (69.7\% completion rate). Overall, student perceptions of the simulation were positive as evidenced by Likert scale responses (Table 3). Thematic content analysis of positive comments indicated student preference for this type of learning, with students asking for "more" simulation opportunities (n=9; eg, "more topics utilizing simulation technology", "more questions on the simulation", "more cases 
made into simulations for additional practice"). The other predominant positive theme from survey comments surrounded "feedback" (n=14; eg, "given immediately", "given for right and wrong answers", "opportunity to reattempt questions after feedback"). Content analysis revealed negative comments pertaining to technical issues (pop-up blockers $(n=6)$, internet browser used $(n=4))$.

\section{DISCUSSION}

In this study, we evaluated the use of a HF virtual patient simulation in a required PY2 pharmacotherapy course. Use of the simulation was associated with improved performance on HF pharmacotherapy examination questions, and student perceptions indicated a preference for this style of learning. Examination performance was improved on both lower and higher order questions in the simulation cohort, though not meeting statistical significance on higher order questions. Performance on the HF questions on the final examination was improved in 2019, but not significantly, which may be due to an inclusion of predominately higher-order HF questions ( $\mathrm{n}=5 / 7,71.4 \%)$ on that examination, which was similar to the proportion of higher order HF question on the final examination in $2018(n=4 / 5,80 \%)$. An application-rich activity should theoretically improve performance on higher order questions, which, virtual simulation technology has been shown to improve previously. ${ }^{12}$ However, it is unclear if virtual patient use results in superior outcomes compared to non-virtual interventions across health professional education. ${ }^{3}$ It is possible that a significant difference in performance on final exam and higher order questions was not reached in our investigation due to the low number of questions per subgroup, or because the 2018 course offering also included an application-rich, non-virtual learning activity (paper cases) that also enhanced student learning.

The time required to create the simulation might be viewed as an impediment to implementation. While the simulation did take $\sim 20$ hours to create in its inaugural year, that resulted in a product that was ready for repeated use. It saved faculty time compared to a traditional paper-based activity as completion and performance was automatically recorded in the course gradebook. Also, additional teaching time was not required to review the case as the feedback was provided immediately to the student at the time of clinical decision making. The immediate feedback capability would not be possible in a paper-based activity and was a frequent theme of comments in the survey.

The use of computer-based simulations depicting some HF content in pharmacy education have been evaluated previously. In a study by Douglass and colleagues, 10 computerized clinical patient simulations with multiple comorbidities (including HF) were created to improve drug therapy problem solving. ${ }^{13}$ Pre-post simulation assessments showed advanced clinical skills; however, performance on HF content was not significantly improved. Al-Dahir and colleagues used a virtual patient simulation (including some HF management) and demonstrated improved post-test scores, but to a lesser degree when compared to problem based learning. ${ }^{14}$ A study by Bindoff and colleagues compared a virtual community pharmacy game to a paper-based alternative, which included recognition of inappropriate beta blocker titration in a HF patient.$^{15}$ Student performance improved to a greater degree with the game compared to the paper alternative, similar to the work in our investigation. Assessment of student perception in each study was favorable overall as was the simulation in our investigation. Heart failure was not the sole focus of these other computer-based simulations, making direct comparisons to our results challenging. To our knowledge, we present the first evaluation of a virtual patient simulation specifically designed to enhance HF knowledge in pharmacy education.

There are limitations to our study. Year to year changes in instruction and assessment could have resulted in improved HF question performance; however, steps were taken to minimize this. Examinations were kept nearly the same from 2018 to 2019 and were administered using ExamSoft (ExamSoft Worldwide, Dallas, Texas) in a secure, proctored environment. Questions and answer choices were randomized and student review of the examination material occurred in an identical proctored environment (examination review). In the examination review, the course instructor reviewed the examination and answered student questions, but students were not allowed anything at their desk to prevent them from transcribing or recording content. The same instructor taught HF both years using the same content, however, in the simulation cohort (2019) the instructor taught using a white board/visualizer rather than PowerPoint for all didactic lectures compared to using this method for only one of four lectures in 2018. The instructor made this change due to student feedback from the 2018 course evaluations stating student preference for this teaching style. Similarly, on course evaluations in 2019, many students commented on the effectiveness of this method compared to PowerPoint, and it is possible that this teaching method may have contributed to the improved performance. The course averages were similar between the 2018 and 2019 cohorts ( $81.4 \%$ versus $81.5 \%$, respectively), so it is less likely that the overall academic aptitude of students in the 2019 cohort played a role, however there were no other baseline comparisons performed (eg, two vs. four-year pre-pharmacy experience). The survey response rate $(\sim 70 \%)$ bears mentioning. No incentive for survey completion (eg, bonus credit) was given. It is possible that respondents were higher course performers which could have resulted in high Likert scores on the survey questions. With the anonymous nature of the survey, student exam performance could not be tied back to survey responses to evaluate for response bias of this nature. 


\section{CONCLUSION}

The use of a HF virtual patient simulation was associated with improved examination performance and was wellreceived by student users. Schools might consider adoption of a similar active learning virtual experience to enhance their curriculum, particularly in a remote-learning environment.

\section{REFERENCES:}

1. Agency for Healthcare Research and Quality. AHRQ's simulation dictionary: A new tool to support patient safety efforts [cited 2020 July 5]. Available from:

https://www.ahrq.gov/sites/default/files/wysiwyg/professionals/quality-patient-safety/patient-safetyresources/research/simulation_dictionary/sim-dictionary.pdf

2. Motola I, Devine LA, Chung HS, Sullivan JE, Issenberg SB. Simulation in healthcare education: a best evidence practical guide. AMEE Guide No. 82. Med Teach. 2013;35(10):e1511-e1530. doi:10.3109/0142159X.2013.818632

3. Cook DA, Erwin PJ, Triola MM. Computerized virtual patients in health professions education: a systematic review and meta-analysis. Acad Med. 2010;85(10):1589-1602. doi:10.1097/ACM.0b013e3181edfe13

4. Vyas D, Bray BS, Wilson MN. Use of simulation-based teaching methodologies in US colleges and schools of pharmacy. Am J Pharm Educ. 2013;77(3):53. doi:10.5688/ajpe77353

5. Seybert AL, Smithburger PL, Benedict NJ, Kobulinsky LR, Kane-Gill SL, Coons JC. Evidence for simulation in pharmacy education. J Am Coll Clin Pharm. 2019;2:686- 692. https://doi.org/10.1002/jac5.1167

6. Huang G, Reynolds R, Candler C. Virtual patient simulation at US and Canadian medical schools. Acad Med. 2007;82(5):446-451. doi:10.1097/ACM.0b013e31803e8a0a

7. Smith MA, Mohammad RA, Benedict N. Use of virtual patients in an advanced therapeutics pharmacy course to promote active, patient-centered learning. Am J Pharm Educ. 2014;78(6):125. doi:10.5688/ajpe786125

8. Benedict N, Schonder K, McGee J. Promotion of self-directed learning using virtual patient cases. Am J Pharm Educ. 2013;77(7):151. doi:10.5688/ajpe777151

9. Benjamin EJ, Blaha MJ, Chiuve SE, et al. American Heart Association Statistics Committee and Stroke Statistics Subcommittee. Circulation. 2017;135(10):e146-e603.

10. Milfred-Laforest SK, Chow, SL, DiDomenico RJ, et al., Clinical pharmacy services in heart failure: an opinion paper from the Heart Failure Society of America and American College of Clinical Pharmacy Cardiology Practice and Research Network. J Card Fail. 2013;19(5):354-69.

11. Bloom BS. Taxonomy of educational objectives: the classification of educational goals. New YorkNY: Longmans, Green; 1956

12. Lichvar AB, Hedges A, Benedict NJ, Donihi AC. Combination of a Flipped Classroom Format and a Virtual Patient Case to Enhance Active Learning in a Required Therapeutics Course. Am J Pharm Educ. 2016;80(10):175. doi:10.5688/ajpe8010175

13. Douglass MA, Casale JP, Skirvin JA, DiVall MV. A virtual patient software program to improve pharmacy student learning in a comprehensive disease management course. Am J Pharm Educ. 2013;77(8):172. doi:10.5688/ajpe778172

14. Al-Dahir S, Bryant K, Kennedy KB, Robinson DS. Online virtual-patient cases versus traditional problem-based learning in advanced pharmacy practice experiences. Am J Pharm Educ. 2014;78(4):76. doi:10.5688/ajpe78476

15. Bindoff I, Ling T, Bereznicki L, et al. A Computer Simulation of Community Pharmacy Practice for Educational Use. Am J Pharm Educ. 2014;78(9):168. doi:10.5688/ajpe789168 
Table 1. Heart Failure Content Comparison in PY2 Pharmacotherapeutics Course

\begin{tabular}{|c|c|c|}
\hline & 2018 (Control) & 2019 (Intervention) \\
\hline Class Contact hours & 6 & 6 \\
\hline Number of classes & 4 & 4 \\
\hline Class Topics & $\begin{array}{l}\text { 1: HF Overview } \\
\text { 2-3: Chronic HF } \\
\text { 4: ADHF }\end{array}$ & $\begin{array}{l}\text { 1: HF Overview } \\
\text { 2-3: Chronic HF } \\
\text { 4: ADHF }\end{array}$ \\
\hline Lecture Pedagogy & $\begin{array}{l}\text { Class 1: Written/drawn notes }{ }^{\mathrm{a}} \\
\text { Classes } 2-4: \text { Powerpoint }\end{array}$ & Written/drawn notes for all classes \\
\hline Clinical Case & $\begin{array}{l}\text { Two, deidentified hospitalized } \\
\text { patient cases on paper with } \\
\text { admission subjective/objective data } \\
\text { provided }\end{array}$ & $\begin{array}{l}\text { Branched-linear virtual patient } \\
\text { simulation following one patient } \\
\text { across the continuum of HF care }\end{array}$ \\
\hline Clinical Case Assignment & $\begin{array}{l}\text { Guided worksheet SA questions ( } \mathrm{n} \\
=9 \text { ) }\end{array}$ & $\begin{array}{l}\text { Embedded MC questions }(n=13) \\
\text { within the simulation }\end{array}$ \\
\hline \multicolumn{3}{|l|}{ Clinical Case Assessment } \\
\hline Grade assigned & Completion (yes/no) & Completion (yes/no) \\
\hline Individualized Feedback provided & None & Yes \\
\hline \multicolumn{3}{|l|}{ Clinical Case Recitation } \\
\hline Hours & 1 (optional) & 0 \\
\hline Recitation Pedagogy & Clinical case debrief & N/A \\
\hline Total HF Examination Questions & 14 & 18 \\
\hline HF section examination & 9 & 11 \\
\hline HF final examination & 5 & 7 \\
\hline Lower order questions ${ }^{c}$ & 6 & 8 \\
\hline Higher order questions $^{\mathrm{d}}$ & 8 & 10 \\
\hline \multicolumn{3}{|c|}{$\begin{array}{l}\text { a Using a visualizer or white board, }{ }^{\mathrm{b}} \text { Continuum of HF care consisted of three "scenes" with different presentations at different } \\
\text { time points (eg, initial myocardial infarction, initial ADHF emergency department presentation two years later, and advanced } \\
\text { HF hospital admission } 15 \text { years later), }{ }^{\mathrm{c}} \text { Defined as Bloom's taxonomy "knowledge or comprehension" level, }{ }^{\mathrm{d}} \text { Defined as } \\
\text { Bloom's taxonomy "application or synthesis" level } \\
\text { HF = Heart failure, ADHF = Acute decompensated heart failure, SA = Short answer, MC = Multiple choice }\end{array}$} \\
\hline
\end{tabular}

Table 2. Pharmacotherapeutic Heart failure Examination Question Performance

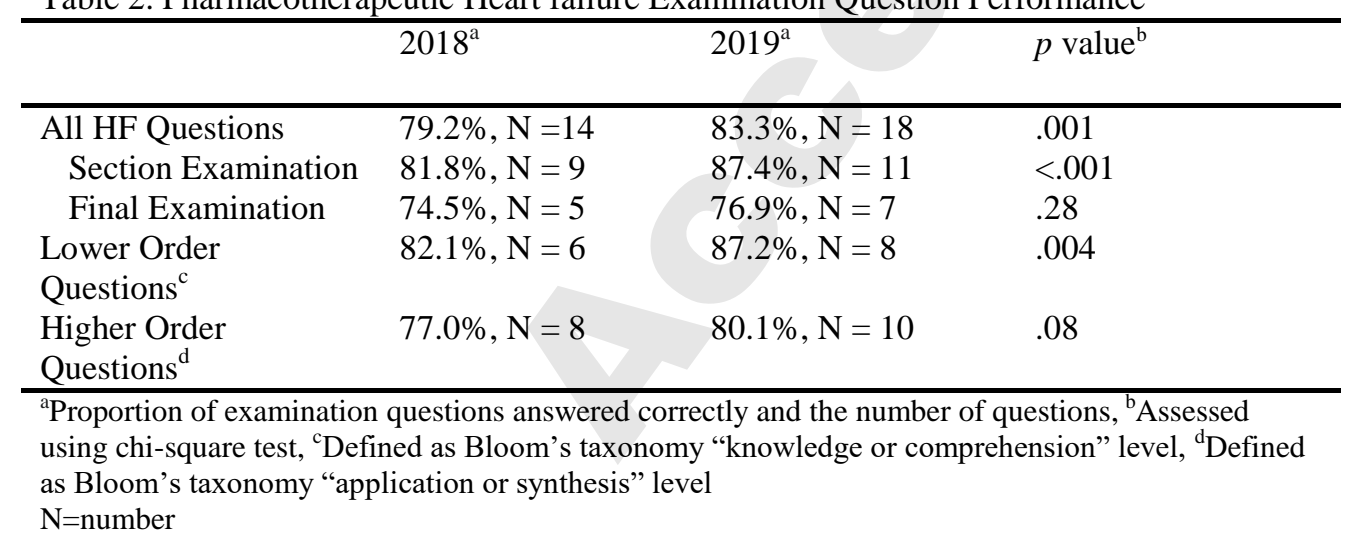


Table 3. Student Perception Survey Results ${ }^{\mathrm{a}}$

\begin{tabular}{|c|c|c|c|c|c|}
\hline Item & $\mathrm{M}(\mathrm{SD})^{\mathrm{b}}$ & $\begin{array}{l}\text { Median } \\
(\mathrm{IQR})^{\mathrm{b}}\end{array}$ & $\begin{array}{l}\text { Disagree }^{\mathrm{c}}, \\
\mathrm{N}(\%)\end{array}$ & $\begin{array}{l}\text { Neutral, } \\
\mathrm{N}(\%)\end{array}$ & $\begin{array}{l}\text { Agree }^{\mathrm{d}}, \mathrm{N} \\
(\%)\end{array}$ \\
\hline $\begin{array}{l}\text { The information provided to me through in- } \\
\text { class materials (eg, lecture content) } \\
\text { appropriately prepared me for the simulation. }\end{array}$ & $4.41(0.68)$ & $4(4-5)$ & $2(2.4)$ & 0 & $83(97.7)$ \\
\hline $\begin{array}{l}\text { The online learning simulation enhanced my } \\
\text { ability to understand the material presented } \\
\text { during class. }\end{array}$ & $4.55(0.66)$ & $5(4-5)$ & $1(1.2)$ & $2(2.4)$ & $82(96.5)$ \\
\hline $\begin{array}{l}\text { The online learning simulation enhanced my } \\
\text { ability to apply the material taught during } \\
\text { class to the management (eg, drug selection) } \\
\text { of a patient case. }\end{array}$ & $4.59(0.58)$ & $5(4-5)$ & $1(1.2)$ & $1(1.2)$ & 83 (97.7) \\
\hline $\begin{array}{l}\text { The immediate feedback provided to me after } \\
\text { making a clinical decision } \\
\text { in the simulation was valuable to my } \\
\text { learning }\end{array}$ & $4.62(0.56)$ & $5(4-5)$ & $1(1.2)$ & 0 & $84(98.8)$ \\
\hline $\begin{array}{l}\text { The simulation enhanced my clinical } \\
\text { pharmacy skills } \mathrm{s}^{\mathrm{f}} \text { to a greater degree than } \\
\text { traditional lecture }{ }^{\mathrm{g}} \text {. }\end{array}$ & $4.54(0.66)$ & $5(4-5)$ & $1(1.2)$ & $2(2.4)$ & $82(96.5)$ \\
\hline $\begin{array}{l}\text { Completing the simulation had a positive } \\
\text { impact on my examination performance. }\end{array}$ & $4.34(0.84)$ & $5(4-5)$ & $2(2.4)$ & $8(9.4)$ & 74 (87.1) \\
\hline $\begin{array}{l}\text { It would be beneficial for other topics within } \\
\text { the pharmacotherapeutics course sequence to } \\
\text { incorporate the use of online simulations } \\
\text { similar to this one. }\end{array}$ & $4.66(0.57)$ & $5(45)$ & $1(1.2)$ & $1(1.2)$ & 83 (97.7) \\
\hline $\begin{array}{l}\text { Approximate amount of time (in minutes) } \\
\text { spent using the simulation }\end{array}$ & $46.6(30.5)$ & --- & & & --- \\
\hline
\end{tabular}

${ }^{\mathrm{a}} \mathrm{n}=85 / 122$ (69.7\% response rate), ${ }^{b}$ Likert scale: 1 - strongly disagree, 2 - disagree, 3 - neutral, 4 - agree, 5 - strongly agree,

${ }^{\mathrm{c}}$ Strongly disagree and disagree ratings pooled, ${ }^{\mathrm{d}}$ Agree and strongly agree ratings pooled, ${ }^{\mathrm{e}}$ Examples of clinical decisions in the simulation were given on the survey and included: recommending appropriate therapy, staging patients appropriately, recommending and interpreting monitoring parameters, etc., ${ }^{\mathrm{f}}$ Clinical pharmacy skills were defined in the survey as the skills needed to provide patient care that optimizes medication therapy and promotes health, wellness and disease prevention, ${ }^{\mathrm{g}}$ Traditional lecture was defined in the survey as a didactic lecture given with a PowerPoint presentation $\mathrm{M}=$ Mean, $\mathrm{SD}=$ standard deviation, $\mathrm{IQR}=$ interquartile range, $\mathrm{n}=$ number 